\title{
Factors Influencing Competency Perceptions and Expectations of Technical Services Administrators
}

\section{Norm Medeiros}

This study investigates the factors that influence perceived and expected daily task competencies for technical services administrators; that is, the competencies technical services administrators claim to possess (perceived) and those they believe they ought to possess (expected) in the areas of acquisitions, cataloging, and serials. For the purposes of this paper, a technical services administrator is defined as one who oversees, at a minimum, the acquisitions, cataloging, and serials units in his or her library. The author surveyed 116 technical services administrators via e-mail in fall 2003, receiving a response rate of 54 percent and an acceptable use rate of 53 percent. The survey was designed to correlate perceived and expected competencies with: (1) an incumbent's professional background; (2) tenure in current position at present institution; and (3) size of technical services unit as measured in full-time equivalents (FTE). The study concludes that incumbent tenure and size of the technical services unit affect both perceived and expected competencies, with the latter having a greater effect. Professional background affects competency possession, but has only a marginal effect on competency expectation. The findings reveal that administrators with ten or more years in their current positions who have noncataloging backgrounds and at least ten FTE in their technical services units are least likely to know the daily procedures of their technical services units. Administrators with ten or more years in their current positions who have cataloging backgrounds and at least ten FTE in their technical services units are least likely to feel they ought to know the daily procedures of their technical services departments. These administrators are also least likely to have responsibilities that fall outside of technical services.

Norm Medeiros (nmedeiro@haverford. edu) is Coordinator, Bibliographic and Digital Services, Haverford (Pa.) College.
Tn his excellent essay, "Leadership versus Management in Technical Services," 1 Donald Riggs contents, "Leadership begins where management ends." Riggs juxtaposes a technical services manager who is concerned with procedural "know-how" and a technical services leader who is concerned with procedural "know-why." Riggs concludes, "Leaders, not managers, will move technical services into the twenty-first century." The study that follows is the result of the author's interest in learning what perceptions counterparts held towards their roles, specifically how much hands-on know-how they possessed and believed 
they should possess to successfully administer their departments. This study is intended as only a prima facie glimpse of the responsibilities and attitudes of those surveyed. Speculations based on the survey results are meant to encourage further investigation in this area.

\section{Literature Review}

Besides Riggs' essay, surprisingly few papers have been published within the last twenty years that address technical services management, and only a smattering of these that pertain to the role of the administrator. As one would expect, many of these management papers focus on organization of technical services, especially due to changes resulting from automation. Boissonnas offers such a piece, which describes the changes to Cornell's technical services organization. ${ }^{3}$ Boissonnas discusses Cornell's self-study that eventually yielded a less-hierarchical organization. The restructuring resulted in greater delegation to and authority for department heads, which served to increase the flexibility of the technical services unit as a whole. Manning describes how differing organizational structures affect a manager's accomplishments. ${ }^{4}$ Manning details the technical services organizational charts for various university and public libraries, illustrating the many ways divisions can be organized to achieve their goals. Manning relates management with organization, and recognizes that planning, communication, and specialized knowledge are important criteria for a technical services administrator. Bloss and Lanier point to flexibility as a leading cause of reorganization within technical services departments. ${ }^{5}$ They argue that middle managers soon will have greater influence for coordinating activities between departments, offering staff mentorship, and providing new ideas to their units, rather than their traditional procedural responsibilities. Allen and Williams point to technology as the driving force behind technical services reorganizations. ${ }^{6}$ They consider physical changes necessitated by desktop computers as a force behind changing workflows. As in the articles mentioned earlier, these authors consider flexibility a key resultant from such organizational changes, though they do not state how these changes affect the supervisory role of the technical services head.

Gleason and Miller argue for a move towards a "technical services coordinator" rather than the more traditional "assistant director for technical services." The authors contend that positions of assistant director unnecessarily mirror roles played by the director. Further insinuating another management layer between unit heads and decisions is wasteful and unnecessary, the authors maintain, especially given management theory that touts low-level decision-making as being most successful. A technical services coordinator is more apt to keep the bigger picture in mind, making sure interdepartmental processes flow effectively. The authors further argue that organization and facilitation skills are more important than a strong technical services background, as such a background could cause the coordinator to intrude upon department head decisions. Younger and Gapen offer a historic perspective on technical services divisions and, like Gleason and Miller, note the differences between coordination and direction. ${ }^{8}$ They contend that libraries are moving away from a hierarchical centralization of traditional technical services departments under an associate director and into organizations where the department heads are vested with authority for their units. Accepting Gleason and Miller's and Younger and Gapen's contentions, what competencies are appropriate for a technical services administrator today?

\section{Research Method}

The author distributed an electronic survey to 116 technical services administrators during fall 2003 (see appendix). The survey response rate was 54 percent, with an acceptable use rate of 53 percent. Survey recipients were chosen at random from the American Library Directory. ${ }^{9}$ Surveys were distributed to an even number of administrators at large (more than 15,000 students), medium-to-large (10,000 to 14,999 students), small-to-medium (5,000 to 9,999 students), and small (fewer than 5,000 students) institutions. The survey scope was limited to three traditional technical services areas: acquisitions, cataloging, and serials. The survey covered:

- the respondent's tenure as technical services administrator at his or her present institution;

- the respondent's professional background prior to becoming a technical services administrator;

- the respondent's ability to perform daily tasks in each of the three departments;

- the degree to which the respondent felt he or she should have the knowledge to perform daily tasks in these units;

- additional responsibilities the respondent held in the library (eight options were listed: archives and preservation, bibliographic instruction, collection development, computer hardware and software administration, digital projects, reference desk, Web development, and other); and

- comments on the changing nature of the respondent's position.

The survey was designed to measure the effects of professional background, incumbency tenure, and depart- 
mental staffing on perceived and expected competencies. The rate of other responsibilities was measured, though considered neither an independent nor dependent variable since knowing whether these rates were causal or resultant cannot be readily determined.

An inherent problem with the survey discovered during analysis of the results was the lack of questioning as to why a respondent felt she ought to possess procedural competency in a given area. Since it is possible, likely even, that some respondents answered affirmatively because they do not have a professional librarian in a particular department, an adjusted expectation rate was included in the results. The adjusted expectation removes affirmative answers from the equation when a department does not have a professional FTE within it. As an example, if ten of thirty respondents claim they ought to know the daily procedures of the serials department, and five of these ten affirmative-responding administrators do not have a professional FTE in their serials departments, these five affirmative results are excluded as part of the adjusted measurement. The result, in this example, is an adjusted expectation rate of 20 percent (five of twenty-five) compared to an unadjusted rate of 33 percent (ten of thirty). Clearly, future studies must seek to learn the reasons behind expectation responses.

\section{Results}

The responses reflect the equitable demographic distribution of the survey. Of the sixty-one acceptable responses, twenty were from large institutions, ten from medium-tolarge institutions, eleven from small-to-medium institutions, and twenty from small institutions. The results draw on three independent variables: professional background, incumbent tenure as technical services administrator at his or her current institution, and combined number of FTE in the respondent's technical services division. The rate of other library responsibility was measured. As mentioned above, an adjusted expectation rate based on availability of at least one professional FTE in each department was also included. This adjustment takes into account the possibility a technical services administrator would express expectation of daily task competency to offset not having a professional librarian in a particular department.

The first study compared the perceived and expected competencies of technical services administrators with a cataloging background versus those with a background other than in cataloging (see table 1).

The perceived and expected competency rates for acquisitions show little difference. After adjustment, administrators with a noncataloging background expect to have significantly greater competency, perhaps because 34 percent of these administrators have a background in acquisitions. By comparison, 52 percent of respondents identified themselves as having a cataloging background, 7 percent identified themselves as having a serials background, and 7 percent identified themselves as having a background outside of technical services. Perceived and expected competency values are greatest in the area of cataloging. Even after adjustment, 41 percent of administrators with a cataloging background felt they ought to have daily task competencies, revealing perhaps an ownership urge for cataloging-related activities in their libraries. In the area of serials, administrators with a cataloging background have greater competency in this area, perhaps due to cross pollination of serials and cataloging. The adjusted expectation rates, however, are fairly equal between administrators with cataloging and noncataloging backgrounds.

The overall perceived competency rate for administrators with cataloging backgrounds is significantly greater than for administrators with noncataloging backgrounds, attributable to the very high perceived competency rate (81.25 percent) in the area of cataloging. Even though the majority of administrators with noncataloging backgrounds have backgrounds in acquisitions, the same high perceived competency rate does not exist in the acquisitions area. This may mean that administrators with a cataloging background retain and continue to develop their cataloging skills at a level appropriate for front-liners, whereas the same may not be true for administrators with an acquisitions background. The overall expected competency rates are much closer for the noncataloging and cataloging backgrounds, and the adjusted rates are closer still. With the exception of computer hardware and software administration, technical services administrators with noncataloging backgrounds are more involved in other library operations. Such involvement outside of technical services may encumber more of their time, leaving less to apply toward the daily tasks of their technical services units. This involvement may be one cause for the lower perceived competency rates for administrators with noncataloging backgrounds when compared to those with cataloging backgrounds.

The second study compared perceived and expected competencies of respondents with ten or more years as technical services administrator at their current institutions, versus those administrators with fewer than ten years of tenure as administrator at their current institutions (see table 2).

Administrators with fewer than ten years of experience in their current positions expressed greater perceived and expected competencies for tasks within each of the three departments. One wonders if this greater competency percentage is attributable to these administrators being more recently removed from the trenches and, therefore, still maintaining skill sets even after moving into their current administrative positions. Alternatively, perhaps the 
administrators with more than ten years of experience recognize a need on their part to remove themselves from the daily tasks of their units in order to focus on other issues. Since a number of respondents indicated that personnel and human resources issues were a significant source of time expenditure for them, these more senior administrators are more likely to have such responsibilities placed on them. Curiously, the rate of other responsibility was a bit higher for administrators with fewer than ten years as technical services administrator, perhaps substantiating claims of a generalist trend among newer librarians.

The third study compared the perceived and expected competencies of technical services administrators with ten or more FTE in their divisions versus those administrators with fewer than ten FTE in their divisions (see table 3).

The contrast between these two groups is stark, though not surprising. With the exception of the adjusted serials expectation rate, administrators with fewer than ten FTE in their technical services units possessed considerably greater daily task competency and felt they ought to possess such competency. The fewer staff to which duties can be delegated no doubt forces technical services administrators from smaller libraries to maintain more hands-on expertise. These administrators are no less active in nontechnical services areas in their libraries when compared to administrators who oversee technical services units with ten or more FTE.

Examining responsibility rates for activities outside of traditional technical services areas reveals that administrators at smaller institutions as a group are more actively involved in collection development and reference work, whereas administrators at larger institutions as a group are more actively involved in digital initiatives, archives and preservation, and Web development.

\section{Discussion}

The comments of numerous respondents indicate that technical services administrators are spending significantly more time on management issues in their libraries today than in years past. Some of the comments that indicate this

Table 1. Professional background

\begin{tabular}{|c|c|c|}
\hline & Noncataloging (\%) & Cataloging (\%) \\
\hline Perceived competency of acquisitions daily tasks & 51.72 & 53.13 \\
\hline Expected competency of acquisitions daily tasks & 37.93 & 34.38 \\
\hline Adjusted expectation based on professional FTE in acquisitions dept. & 31.03 & 18.75 \\
\hline Perceived competency of cataloging daily tasks & 55.17 & 81.25 \\
\hline Expected competency of cataloging daily tasks & 31.03 & 43.75 \\
\hline Adjusted expectation based on professional FTE in cataloging dept. & 27.59 & 40.63 \\
\hline Perceived competency of serials daily tasks & 51.72 & 59.38 \\
\hline Expected competency of serials daily tasks & 27.59 & 31.25 \\
\hline Adjusted expectation based on professional FTE in serials dept. & 20.69 & 15.63 \\
\hline Overall perceived competency rate & 52.87 & 64.58 \\
\hline Overall expected competency rate & 32.18 & 36.46 \\
\hline Overall adjusted expected competency rate & 26.44 & 25.00 \\
\hline \multicolumn{3}{|l|}{ Other responsibilities } \\
\hline Archives and preservation & 27.59 & 18.75 \\
\hline Bibliographic instruction & 17.24 & 15.63 \\
\hline Collection development & 68.97 & 56.25 \\
\hline Computer hardware and software administration & 31.03 & 34.38 \\
\hline Digital initiatives & 24.14 & 18.75 \\
\hline Reference desk & 37.93 & 28.13 \\
\hline Web development & 20.69 & 18.75 \\
\hline Other & 34.48 & 28.13 \\
\hline Rate of other responsibilities & 32.76 & 27.35 \\
\hline
\end{tabular}


trend are: "My position has become much more managerial"; "More time is devoted to working upward with library administrators"; and "The primary change has been less involvement in operations and more in administration."

Technology is also noted as a reason for a decline in daily task competencies. A number of respondents commented on the ways technology has left them less knowledgeable about the daily work in their units. Some of these comments are: "Technology has made jobs in cataloging, acquisitions, and serials much more specialized"; "Computerization has led me to become less knowledgeable in the details of day to day procedures"; and "Most tasks are now computer-related and it is very time-consuming trying to keep up."

Given these comments, one can infer administrators with ten or more years in their current positions have significant managerial responsibilities that often take them away from the daily work of their unit. More senior administrators who are also among the subgroup having units with ten or more FTE have likely vested responsibility with department heads in order to free time towards managerial needs. Thus, little need exists for these administrators to maintain task competency. Moreover, since task competency requires proficiency with ever-changing technologies, it may not be a stretch to believe that less senior administrators are more familiar with these technologies and, as a result, are better able to maintain daily task competencies. Equally important to this investigation are administrators' views on whether they ought or ought not possess departmental task competencies. To this end, professional background does not appear to be a factor in expected competency. Position tenure and FTE clearly do affect expected competencies, with the latter being a more significant factor. Administrators with ten or more years in their positions may, by this point in their tenure, have assumed administrative responsibilities within their libraries or campuses or both that necessarily require them to spend less time on the daily activities of their technical services units. These administrators, who have sufficiently large technical services units, may recognize the value in delegating responsibility to department heads. Administrators with fewer than ten years in their positions, on the other hand,

Table 2. Tenure as technical services administrator at present institution

Perceived competency of acquisitions daily tasks

Expressed expected competency of acquisitions daily tasks

Adjusted expectation based on professional FTE in acquisitions dept.

Perceived competency of cataloging daily tasks

Expressed expected competency of cataloging daily tasks

Adjusted expectation based on professional FTE in cataloging dept.

Perceived competency of serials daily tasks

Expressed expected competency of serials daily tasks

Adjusted expectation based on professional FTE in serials dept.

Overall perceived competency rate

Overall expressed expected competency rate

Overall adjusted expected competency rate

Other responsibilities

Archives/preservation

Bibliographic control

Collection development

Computer hardware/software administration

Digital initiatives

Reference desk

Web development

Other
At least ten years (\%)

50.00

26.92

15.38

61.54

34.62

30.77

53.85

23.08

15.38

55.13

28.21

20.51

26.92

11.54

61.54

34.62

19.23

19.23

11.54

30.77

26.92
Fewer than ten years (\%)

54.29

42.86

28.57

74.29

40.00

37.14

57.14

34.29

20.00

61.90

39.05

28.57

20.00

20.00

62.86

31.43

22.86

42.86

25.71

31.43

32.14 
may not yet be vested with the same administrative responsibility within their libraries or campuses. Administrators with fewer than ten FTE in their units are often part of the regular work force, and therefore more easily maintain, and feel they ought to maintain the skills necessary to contribute to their technical services departments.

\section{Conclusion}

Future study must determine why administrators feel they ought to know daily departmental tasks. Including such a question would control for cases where administrators feel responsible for task competencies because no professional librarian resides within the department. Additionally, more detail about the time spent managing, coordinating, and collaborating within one's library, campus, or both will provide a more complete picture of the pressures placed on administrators' time. Perhaps investigating outcomes of the varying attitudes towards competency possession and expectation would offer a glimpse into the success of particular administrative styles. Including such an assessment component may contribute to professional development for new or aspiring technical services administrators.

\section{References}

1. Donald E. Riggs, "Leadership versus Management in Technical Services," in Developing Leadership Skills: A Source Book for Librarians, eds. Rosie L. Albritton and Thomas W. Shaughnessy (Englewood, Colo.: Libraries Unlimited, 1990), 266.

2. Ibid., 234

3. Christian M. Boissonnas, "Managing Technical Services in a Changing Environment: The Cornell Experience," Library Resources \& Technical Services 41, no. 2 (1997): 147-54.

4. Leslie A. Manning, "Technical Services Administration," in Library Technical Services: Operations and Management, ed. Irene P. Godden, 249-59 (Orlando, Fla.: Academic Pr., 1984).

5. Alex Bloss and Don Lanier, "The Library Department Head in the Context of Matrix Management and Reengineering," College \& Research Libraries 58, no. 6 (1997): 499-508.

Table 3. FTE in technical services division

\begin{tabular}{|c|c|c|}
\hline & $\begin{array}{c}\text { At least } \\
\text { ten FTE }(\%)\end{array}$ & $\begin{array}{c}\text { Fewer than ten } \\
\text { FTE (\%) }\end{array}$ \\
\hline Perceived competency of acquisitions daily tasks & 36.67 & 67.74 \\
\hline Expressed expected competency of acquisitions daily tasks & 20.00 & 51.61 \\
\hline Adjusted expectation based on professional FTE in acquisitions dept. & 20.00 & 29.03 \\
\hline Perceived competency of cataloging daily tasks & 53.33 & 83.87 \\
\hline Expressed expected competency of cataloging daily tasks & 16.67 & 58.06 \\
\hline Adjusted expectation based on professional FTE in cataloging dept. & 16.67 & 51.61 \\
\hline Perceived competency of serials daily tasks & 50.00 & 61.29 \\
\hline Expressed expected competency of serials daily tasks & 26.67 & 32.26 \\
\hline Adjusted expectation based on professional FTE in serials dept. & 20.00 & 16.13 \\
\hline Overall perceived competency rate & 46.67 & 70.97 \\
\hline Overall expressed expected competency rate & 21.11 & 47.31 \\
\hline Overall adjusted expected competency rate & 18.89 & 32.26 \\
\hline \multicolumn{3}{|l|}{ Other responsibilities } \\
\hline Archives/preservation & 26.67 & 19.35 \\
\hline Bibliographic control & 13.33 & 19.35 \\
\hline Collection development & 50.00 & 74.19 \\
\hline Computer hardware/software administration & 36.67 & 29.03 \\
\hline Digital initiatives & 26.67 & 16.13 \\
\hline Reference desk & 13.33 & 51.61 \\
\hline Web development & 23.33 & 16.13 \\
\hline Other & 36.67 & 25.81 \\
\hline Rate of other responsibilities & 28.33 & 31.45 \\
\hline
\end{tabular}


6. Nancy H. Allen and James F. Williams, "The Future of Technical Services: An Administrative Perspective," Advances in Librarianship 19, no? (1995): 159-89.

7. Maureen L. Gleason and Robert C. Miller, "Technical Services: Direction or Coordination?" Technical Services Quarterly 4, no. 3 (1987): 13-19.
8. Jennifer Younger and D. Kaye Gapen, "Technical Services Organization," in Technical Services Today and Tomorrow, 2nd ed., ed. Michael Gorman, 165-81 (Englewood, Colo.: Libraries Unlimited, 1998).

9. American Library Directory, 57th ed. (Medford, N.J.: Information Today, 2004).

\section{Appendix. Invitation and Survey}

Dear < survey respondent>,

I am conducting a survey of technical services coordinators to learn how their responsibilities have changed over time. The results of this survey will be used as a component of my research in this area.

The survey should take no more than five minutes to complete if you choose to participate. I will keep your responses confidential. The survey is available at: <survey URL $>$.

Thanks for your help.

Best regards,

Norm Medeiros

Coordinator, Bibliographic and Digital Services

Haverford College

nmedeiro@haverford.edu

\section{Technical Services Coordinator Profile}

1. How many students attend your institution?

_ 15,000+ _ 10,000-14,999 _ 5,000-9,999

— fewer than 5,000

2. How many FTE work in technical services (acquisitions, cataloging, and serials)?

$-50+\ldots 40-49-30-39-20-29-10-19$

- fewer than 10

3. How many professional FTE work in acquisitions?

${ }^{20+}{ }^{20}{ }^{15-19}$ - $^{10-14}$ - $^{5-9}$ - $^{1-4}$

none

4. How many professional FTE work in cataloging?

${ }^{20+}{ }^{20}{ }^{15-19}-^{10-14}-^{5-9}-^{1-4}$

none

5. How many professional FTE work in serials?

${ }^{20+}{ }^{20}{ }^{15-19}$ - $^{10-14}$ - $^{5-9}$ - $^{1-4}$

none

6. How many years have you been the technical services coordinator at your current institution?

$-25+-20-24-15-19-10-14-5-9$

fewer than 5

7. Including all institutions at which you've worked, how many years have you been a technical services coordinator?

$-25+-20-24-15-19-10-14-5-9$

fewer than 5

8. Prior to becoming a technical services coordinator, in which department was your primary responsibility?

_ Acquisitions _ Cataloging _ Serials

- Other (please specify)

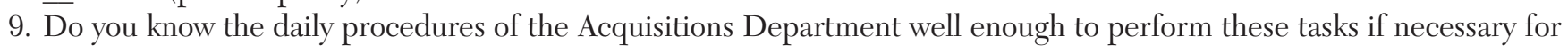
an extended period of time? Yes _ No _ Not sure

10. How long do you think it would take you to learn the daily tasks of the Acquisitions Department? _ less than a month _ $3-6$ months _ 1-2 months _ more than 6 months 
11. Do you know these daily procedures as well or better than everyone in the Acquisitions Department? Yes _ No _ Not sure

12. Do you think you should know these daily procedures as well or better than the Acquisitions staff? _ Yes _ No _ Not sure

13. Do you know the daily procedures of the Cataloging Department well enough to perform these tasks if necessary for an extended period of time? Yes _ No _ Not sure

14. How long do you think it would take you to learn the daily tasks of the Cataloging Department? _ less than a month _ 3-6 months _ 1-2 months _ more than 6 months

15. Do you know these daily procedures as well or better than everyone in the Cataloging Department? Yes _ No _ Not sure

16. Do you think you should know these daily procedures as well or better than the Cataloging staff? _ Yes _ No _ Not sure

17. Do you know the daily procedures of the Serials Department well enough to perform these tasks if necessary for an extended period of time? _ Yes _ No _ Not sure

18. How long do you think it would take you to learn the daily tasks of the Serials Department? _ less than a month _ 3-6 months _ _ 1-2 months _ more than 6 months

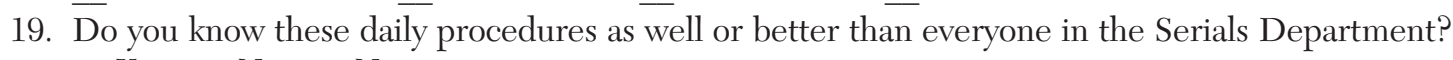
_ Yes _ No _ Not sure

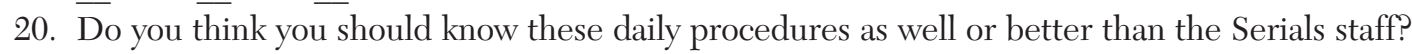
Yes _ No _ Not sure

21. What activities outside of technical services do you perform (please check all that apply)? - Archives/preservation

— Bibliographic instruction

- Collection development

_ Computer hardware/software administration

_ Digitization projects

— Reference desk

_ Web development _ Other (please specify)

22. $\bar{C}$ Comments you'd like to make regarding how your responsibilities as a technical services coordinator have changed over time. 